\title{
The Construction and Application of Micro Learning Environment Under the Background of New Media
}

\author{
Yan Zhou \\ Nanchang Institute of Science \& Technology, Nanchang,330108, China
}

Key words: New media; Informal learning; Micro learning; Micro classroom; Micro course

\begin{abstract}
This paper takes a new model of learning realization --- micro learning as the research background under the background of new media, and thoroughly studies the construction and application of micro learning environment under the background of new media. First, the concepts and related technologies of new media and micro learning are expounded. Secondly, the design of micro learning under the background of new media is deeply studied. Finally, the practical application process of micro learning under the environment of new media is discussed.
\end{abstract}

\section{Introduction}

In recent years, the new media has brought profound influence to the educational field at the speed of rapid development. Under the background of current new media, a number of new learning forms have emerged, including micro learning, ubiquitous learning, mobile learning and so on ${ }^{[1]}$. These informal learning forms bring challenges and impacts to the traditional education mode, but also bring unprecedented opportunities for development. This paper takes a new model of education and learning --- micro learning as the background under the environment of new media, and discusses the construction and application of micro learning environment under the background of new media.

\section{The concept and characteristics of micro learning}

Micro learning (Micro-Learning) was first proposed by Lindner, a Austria learning and research expert, in 2004. His description of micro learning is " a new learning system based on micro content and micro media in the new media ecosystem" ${ }^{[2]}$. Micro learning usually has the following characteristics ${ }^{[3]}:$ (1) The modularization of learning content: because of the short characteristics of micro learning, so it is necessary to divide the large learning content into small learning modules. (2) The arbitrariness of learning time: learners can make use of scattered time to do related learning without fixed time. (3) The unstability of learning sites: learners can learn at any time and anywhere through the Internet and mobile devices, there is no need for a fixed place ${ }^{[4]}$. (4) The diversity of learning media: micro learning can use not only mobile terminal equipment, with the help of other media, learners can use wireless network technology to learn. (5) The individualization of learning form: learners can selectively learn according to their interests and hobbies when they are doing micro learning.

\section{Micro learning design under the background of new media}

From the point of view for the three elements of micro learning, the design link of the general micro learning classroom consists of three parts: the design of the learning process, the design of the learning resources and the design of the learning evaluation. According to the theory of teaching design, the design of the teaching process usually includes ${ }^{[5]}$ : (1) The design of the course unit: the process of teaching design mainly for a course or a unit. (2) The design of classroom teaching: the process of classroom teaching design mainly for one class (according to the size of knowledge points, takes a number of knowledge points as the unit). (3) The design of autonomous teaching: the process of teaching design mainly takes a certain theme as the background. (4) The design of micro 
teaching: the process of teaching design mainly aimed at a certain knowledge point or activity.

Therefore, according to the design of the teaching process mentioned above, for micro learning, because of its own characteristics, in the process of teaching design, teaching design should be carried out in a certain knowledge point or a certain activity. The overall operation process of micro learning teaching design can be divided into three stages, namely: the determination stage of the theme for micro learning, the specific implementation stage of micro learning and the evaluation stage of micro learning. Figure 1 is an operation process of teaching design for micro learning.

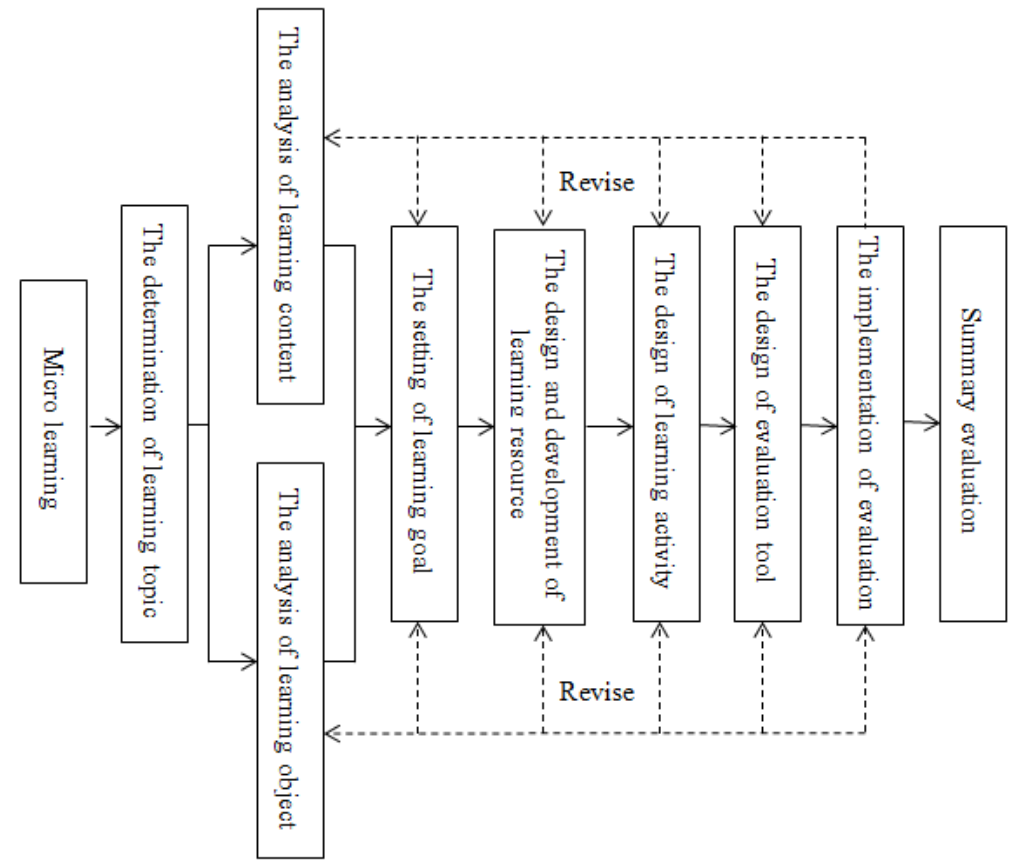

Figure 1 operation process of teaching design for micro learning

(1) The determination of topic: before design the teaching for micro learning, the theme of the course should be determined first.

(2) The analysis of learning content and learning object: the teaching design of micro learning is usually centered on the point of knowledge or theme to design, and the content of teaching should have the characteristics of typicality, integrity, and protrusion, etc.

(3) The setting of learning goal: generally speaking, the learning objectives have the characteristic of pluralism, not only have the need to acquire knowledge, but also have the need to enhance their related abilities. Therefore, in the design of micro course, we should take into account the needs of learners for term goals.

(4) The design and development of learning resource: the design and development of micro learning resources, not only can use the traditional media (paper textbooks, newspapers, etc.), but also can use the new media tools (such as Internet, computer and smart phone terminal equipment) to engage in the construction of related resources.

(5) The design of learning activity: learning activity is an important part of micro learning design, and different learning contents need different learning activities. The design of learning activities needs to be carefully designed by teachers, and then completed by learners.

(6) The design of evaluation tool: in the process of micro learning, the evaluation link is also an important part. In order to evaluate learners' learning state and result effectively, it is necessary to establish learning evaluation links. In design, evaluation criteria and standard of learning are usually given.

(7) The implementation of evaluation: when the learners study in accordance with the learning task, and need to work together with the teacher to complete the evaluation of the study. According to the feedback information, the learning activities and the teaching design are corrected and 
perfected.

\section{The exploration and practice of micro learning under the background of new media}

\subsection{The design and establishment of micro classroom and micro course}

In the process of the design and construction for micro course, we have certain pertinence and prominence to the design of micro course, which are mainly manifested in several aspects: (1) Each class of micro course is based on a certain point of knowledge, a topic or a simple experiment as the theme. (2) The design of teaching contents highlights typicality, representativeness and universality, etc. (3) The categories of micro course are as varied as possible, such as teaching, experiment and problem solving, etc. (4) The design of the micro course is as complete and independent as possible.

Micro course seems simple and content is short, but in the process of actual design, it is found that there is still a certain degree of difficulty. For every lightweight micro course, it is a difficult design to make a complete teaching process in a short time, to ensure the clarity and integrity of the classroom content, and to be easy to understand, this is a hard work of design. Therefore, in the process of the design and construction for the micro course, we have chosen some of the teachers with a strong teaching design and teaching experience to make up a group of course practice teams to undertake the design of the related micro courses.

\subsection{Building a personalized and autonomous learning model}

Under the environment of traditional media, due to the constraints of many factors, traditional classroom teaching can not meet the needs of most students' personalized learning. The traditional "popular" education and teaching mode, most of the situation is a teaching process of "teacher centered", students in the study, basically in a passive learning state. The orientation of teachers' teaching goals is based on the general student level. In the aspect of teaching methods, models and textbooks selection, there is almost no difference, and all tend to be similar or identical. The individualized teaching policy of "teaching students in accordance with their aptitude and being suitable for others" is not well reflected in traditional classroom teaching.

However, in the era of new media, this situation is changing. Due to the rapid development of information technology and new media, massive digital teaching and learning resources have emerged on the Internet. The emergence of new media also provides learners with a better learning environment. The convenience of this sequence provides more space for the students to learn independently, thus providing personalized and differentiated learning opportunities for more students.

The age of the socialization and the knowledge gradual updating and accelerating, the traditional classroom education has been unable to meet the needs of people's lifelong learning because of the constraints of time and space. At present, computer science is developing not only in the deep field, but also in the interdisciplinary way. Therefore, in the era of the continuous development of this knowledge system and the continuous increase of knowledge content and structure, the limited education time of the school can not meet the needs of the society. Therefore, cultivating students' autonomous learning ability is very necessary for students' future development. In daily practice, we have established an autonomous learning mode centered on students' interests. In the specific implementation process, we have established a number of digital resources such as micro courses. In these micro courses, apart from the pure knowledge of micro courses, but also developed some knowledge, games and skills of micro operation. We should integrate interesting and practical elements into the design of micro course so as to enhance students' interest in related courses.

\subsection{Establishing a micro learning community supported by "new media"}

With the development of information technology and new media, the mode of vocational education teaching has presented a pluralistic situation. The single learning mode of traditional classroom has changed, and various new vocational education teaching platforms have emerged. At present, many large-scale open web courses are attacking the teaching mode under the traditional 
media, and gradually become a useful supplement.

The micro learning community, supported by the "new media", as an open learning community, provides a broader teaching platform for traditional classroom teaching. Whether in time or space, learners will become more free and open in their learning activities. The teaching atmosphere is more harmonious, and the efficiency of teachers and students has also been improved. In addition, with the help of the teaching community platform, teachers and students can publish relevant information and carry out good interaction and communication.

\section{Conclusion}

Micro learning is a new lightweight learning mode born in the new media environment. In recent years, the author analyses that micro learning has been developed rapidly and has been sought after by everyone. The main reasons can be summed up as three points: (1) The concept of micro learning is adapted to the trend of social and cultural development. (2) The characteristics of micro learning are in line with the needs of socialization. (3) The micro learning is the same as the cognitive process based on web learning.

We have reason to believe that in the future, with the continuous development of new media technology and educational reform, the informal learning model, represented by micro learning, will have a wider space for exploration and practice.

\section{References}

[1] Haofeng Zhang, Ximei Zhu. The application of the mobile micro learning in distance education [J]. Continuing education research. 2011 (04): 75-76.

[2] Xiangen Wu. The case and its innovative application of micro video under the background of mobile learning [J]. China Audio-Visual Education, 2012 (06):73-77.

[3] Wei Zhang, Lin Chen, Yan Ding. The concept of learning in the era of mobile learning: based on the viewpoint of distributed cognition, [J]. China Audio-Visual Education, 2010 (04):21-25.

[4] Hao Zhang. Study on the design under the environment of new media. [D]: Nanjing: Doctoral Dissertation of Nanjing Normal University. 2012, 5

[5] Long Li. Analysis on the design and implementation of "micro learning" [J]. Audio-visual education research, 2014 (02): 73-76. 